\title{
Acute Intermittent Porphyria: Identification and Expression of Exonic Mutations in the Hydroxymethylbilane Synthase Gene
}

\author{
An Initiation Codon Missense Mutation in the Housekeeping Transcript Causes "Variant Acute \\ Intermittent Porphyria" with Normal Expression of the Erythroid-specific Enzyme \\ Chia-Hsiang Chen, ${ }^{\star}$ Kenneth H. Astrin, ${ }^{\star}$ Grace Lee, ${ }^{\star}$ Karl E. Anderson, ${ }^{\star}$ and Robert J. Desnick \\ * Department of Human Genetics, Mount Sinai School of Medicine, New York 10029; and ${ }^{\ddagger}$ Division of Human Nutrition, University \\ of Texas Medical Branch, Galveston, Texas 77555
}

\begin{abstract}
Acute intermittent porphyria (AIP), an autosomal dominant inborn error, results from the half-normal activity of the heme biosynthetic enzyme, hydroxymethylbilane synthase (EC 4.3.1.8). Diagnosis of AIP heterozygotes is essential to prevent acute, life-threatening neurologic attacks by avoiding various precipitating factors. Since biochemical diagnosis is problematic, the identification of hydroxymethylbilane synthase mutations has facilitated the detection of AIP heterozygotes. Molecular analyses of unrelated AIP patients revealed six exonic mutations: an initiating methionine to isoleucine substitution (M1I) in a patient with variant AIP, which precluded translation of the housekeeping, but not the erythroid-specific isozyme; four missense mutations in classical AIP patients, V93F, R116W, R201W, C247F; and a nonsense mutation $W 283 X$ in a classical AIP patient, which truncated the housekeeping and erythroidspecific isozymes. Each mutation was confirmed in genomic DNA from family members. The W283X lesion was found in another unrelated AIP family. Expression of each mutation in Escherichia coli revealed that R201W, C247F, and $\mathrm{W} 283 \mathrm{X}$ had residual activity. In vitro transcription/translation studies indicated that the M1I allele produced only the erythroid-specific enzyme, while the other mutant alleles encoded both isozymes. These mutations provide insight into the molecular pathology of classic and variant AIP and facilitate molecular diagnosis in AIP families. (J. Clin. Invest. 1994. 94:1927-1937.) Key words: hydroxymethylbilane synthase $\bullet$ porphobilinogen deaminase $\bullet$ initiation of translation - mutation analysis - single strand conformation polymorphism
\end{abstract}

Address correspondence to R. J. Desnick, Ph.D., M.D., Professor and Chairman, Department of Human Genetics, Mount Sinai School of Medicine, Fifth Avenue at 100th Street, New York, NY 10029.

Received for publication 5 May 1994 and in revised form 7 July 1994.

1. Abbreviations used in this paper: AIP, acute intermittent porphyria; ALA, $\delta$-aminolevulinic acid; ASO, allele-specific oligonucleotide; HMB-synthase, hydroxymethylbilane synthase; PBG, porphobilinogen; SSCP, single-strand conformational polymorphism.

J. Clin. Invest.

(C) The American Society for Clinical Investigation, Inc.

$0021-9738 / 94 / 11 / 1927 / 11 \quad \$ 2.00$

Volume 94, November 1994, 1927-1937

\section{Introduction}

Acute intermittent porphyria (AIP), ${ }^{1}$ an autosomal dominant inborn error of metabolism, results from the half-normal activity of hydroxymethylbilane synthase (EC 4.3.1.8; HMB-synthase), the third enzyme in the heme biosynthetic pathway $(1-4)$. This enzyme, formerly known as porphobilinogen deaminase or uroporphobilinogen I synthase, catalyzes the head to tail condensation of four molecules of porphobilinogen (PBG) to form the linear tetrapyrrole, hydroxymethylbilane. Clinical onset of the disease typically occurs during or after puberty and is characterized by intermittent attacks of neurological dysfunction, including abdominal pain and other gastrointestinal complaints, hypertension, tachycardia, and various peripheral and central nervous system manifestations. Expression of the disease is highly variable, determined in part by environmental, metabolic, and hormonal factors that induce hepatic $\delta$-aminolevulinic acid synthase activity, the first and rate-limiting enzyme of heme biosynthesis, thereby increasing the production of the porphyrin precursors, $\delta$-aminolevulinic acid (ALA) and PBG (5-7). The half-normal hepatic HMB-synthase activity in AIP patients is insufficient to prevent precipitation of the acute, life-threatening symptoms of the disease. Thus, the diagnosis of AIP heterozygotes is crucial as the primary form of medical management is the avoidance of specific precipitating factors.

HMB-synthase is encoded by a single gene localized to the chromosomal region $11 \mathrm{q} 24.1 \rightarrow \mathrm{q} 24.2(8,9)$. Recently, the entire 11-kb gene was sequenced, including the $5^{\prime}$ regulatory, $3^{\prime}$ untranslated, and intronic regions (10). As shown in Fig. 1, the gene contains 15 exons and 2 distinct promoters that generate housekeeping and erythroid-specific transcripts by alternative splicing $(11,12)$. The housekeeping promoter is in the $5^{\prime}$ flanking region and its transcript contains exons 1 and $3-15$. The erythroid-specific promoter is in intron 1 and its transcript is encoded by exons $2-15$. The housekeeping transcript is expressed in all tissues and its promoter has certain features characteristic of housekeeping promoters, while the intron 1 promoter is active in erythroid tissues and has regulatory elements similar to those of the $\beta$-globin gene promoter $(11,13,14)$. cDNAs encoding the $42-\mathrm{kD}$ housekeeping and $40-\mathrm{kD}$ erythroidspecific isozymes, which differ only in their $\mathrm{NH}_{2}$-terminal amino acid sequences, have been isolated and characterized (12, 15). The enzyme from human erythrocytes has been purified to homogeneity and its physical and kinetic properties have been determined (16).

Previous biochemical and immunologic studies have revealed significant genetic heterogeneity in the mutations causing AIP (17-19). Two major subtypes of AIP have been delineated $(7,20)$. In classical AIP, the housekeeping and the erythroid- 

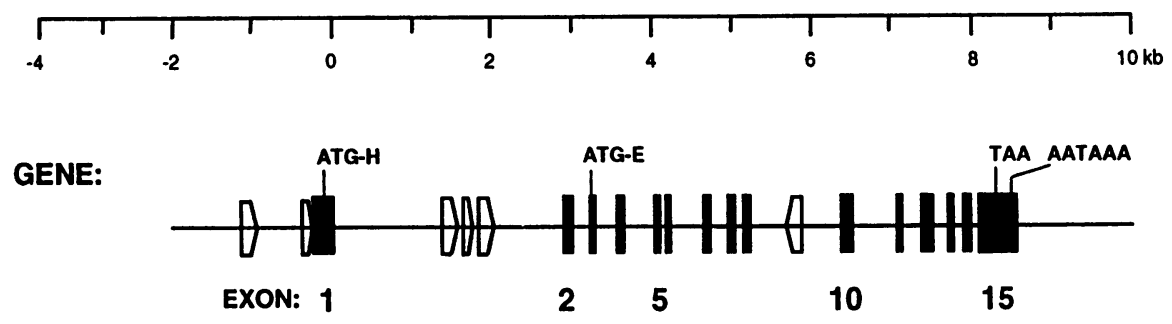

Figure 1. Genomic organization of the human HMB-synthase gene and alternative splicing of the housekeeping and erythroidspecific transcripts. Exons 1-15 are represented as solid rectangles, and the positions and orientations of the Alu repeat elements are indicated by the pentagonal figures. The gene has two promoter regions, $5^{\prime}$ to exon 1 for the housekeeping transcript and 5 ' to exon 2 for erythroid-specific transcript. The initiation of translation sites for the housekeeping (ATG-H) and erythroid-specific (ATG-E) polypeptides are indicated.

specific enzymes both have half-normal activities, whereas in variant AIP (representing 5\% of AIP families) the housekeeping enzyme has half-normal activity, while the erythroid-specific enzyme is expressed at normal levels (21). To date, the molecular lesions in two unrelated families with variant AIP have been identified as different mutations in the intron $15^{\prime}$ donor splice consensus sequence, which preclude normal splicing of the housekeeping transcript $(22,23)$. Symptomatic heterozygotes with classical or variant AIP, who excrete increased levels of the porphyrin precursors, ALA and PBG, can be identified easily, provided that the diagnosis is considered. However, the biochemical diagnosis of asymptomatic heterozygotes who usually have normal levels of urinary ALA and PBG has been problematic by enzyme assay, primarily due to the significant overlap between high heterozygote and low normal values (7, 24-27). Moreover, identification of asymptomatic heterozygotes for variant AIP is not possible as they have normal erythrocyte enzyme activities $(21,28)$. In view of the difficulties with biochemical diagnosis, investigators have turned to molecular techniques to identify diagnostically useful restriction fragment length polymorphisms (RFLPs) and specific mutations in the HMB-synthase gene.

To date, 24 different mutations in the HMB-synthase gene have been detected. Most of these mutations were either private or were found only in a few unrelated families, emphasizing the molecular heterogeneity of the mutations causing this disease (29-41). However, mutations W198X and R116W have been detected in a large number of Swedish and Dutch AIP families, respectively $(33,40)$. In addition, a variety of intragenic RFLPs have been identified which have proven useful for heterozygote diagnosis in informative families whose mutations have not been determined (42-48). However, there is marked linkage disequilibrium for the intron 1 and intron 3 RFLPs in northern European and American populations (49-51), with the exception of a recently identified common intron $10 \mathrm{HinfI}$ site (10).

The recent availability of the entire HMB-synthase genomic sequence (10) has facilitated mutation identification by the single-strand conformational polymorphism (SSCP) technique and by solid-phase direct sequencing. In this communication, six new mutations causing AIP are described. Of particular interest, a missense mutation in the initiation of translation codon of the housekeeping transcript was identified as a novel cause of variant AIP.

\section{Methods}

Patient specimens, enzyme assays, and molecular screening. Peripheral blood samples were collected from nine unrelated classical AIP patients, one patient putatively diagnosed as variant AIP, and their family members with informed consent. Lymphoid cell lines were established and maintained as described previously (52). From each proband, erythrocyte lysates were assayed for HMB-synthase activity (21) and genomic DNA was extracted from peripheral blood $(53,54)$ for detection of known HMB-synthase mutations (IVSI-1, IVSI+1, Q155X, R167Q, R167W, R173Q, W198X, and IVSI2-1) as described previously (29-35).

Detection of HMB-synthase mutations by SSCP. To detect mutations in HMB-synthase gene, SSCP was used as described (55) and modified (56). The 12 primer sets used for amplification of each exon and their flanking intronic sequences were synthesized on a synthesizer (model 380B; Applied Biosystems, Inc., Foster City, CA) and are indicated in Table I. Note that exons 2 and 3, 5 and 6, and 14 and 15 were amplified as single polymerase chain reaction (PCR) products which included the respective intervening introns. Amplifications were performed essentially as described by Saiki et al. (57) with the following modifications. Each 20- $\mu$ l reaction mixture contained $100 \mathrm{ng}$ of genomic DNA; 10 pmol of each primer; $31.25 \mathrm{mM}$ of each dNTP; $5 \mu \mathrm{Ci}\left[\alpha{ }^{35} \mathrm{~S}\right] \mathrm{dATP} ; 10$ $\mathrm{mM}$ Tris- $\mathrm{HCl}, \mathrm{pH} 8.8 ; 50 \mathrm{mM} \mathrm{KCl} ; 1.5 \mathrm{mM} \mathrm{MgCl}_{2} ; 0.1 \%$ Triton X100, and 2.5 U of Taq polymerase (Promega Corp., Madison, WI). After an initial incubation at $94^{\circ} \mathrm{C}$ for $5 \mathrm{~min}$, amplification ( 30 cycles) of each exon (except exon 1) was performed with denaturation at $94^{\circ} \mathrm{C}$ for 1 min, annealing at $60^{\circ} \mathrm{C}$ for $1 \mathrm{~min}$, and extension at $72^{\circ} \mathrm{C}$ for $30 \mathrm{~s}$. To amplify exon 1 , the annealing temperature was raised to $66^{\circ} \mathrm{C}$. Aliquots ( $1 \mu \mathrm{l}$ ) of the amplified DNAs were diluted with $4.5 \mu \mathrm{l}$ of $0.1 \%$ SDS containing $10 \mathrm{mM}$ EDTA and $4.5 \mu \mathrm{l}$ of $95 \%$ formamide loading dye. Samples $(10 \mu \mathrm{l})$ were denatured at $100^{\circ} \mathrm{C}$ for $5 \mathrm{~min}$ and then snapfrozen in ice water. After centrifuging for $30 \mathrm{~s}$ at $4^{\circ} \mathrm{C}$, aliquots $(3 \mu \mathrm{l})$ were electrophoresed in $6 \%$ polyacrylamide gels containing $10 \%$ glycerol at 5-30 W and $4^{\circ} \mathrm{C}$. The gels were dried and exposed to Kodak XAR-5 film for 1-2 d. Amplified fragments showing mobility shifts were subjected to solid-phase direct sequencing by the dideoxy chain termination method (58) using sequencing according to the manufacturer's instructions (United States Biochemical Corp., Cleveland, $\mathrm{OH}$ ).

Detection of HMB-synthase mutations by direct solid-phase sequencing. To facilitate mutation detection directly from genomic DNA, primer sets (with one biotinylated) for the entire coding sequence and 
Table I. Primer Sets for Amplification of HMB-Synthase Coding Exons for SSCP Analysis or Solid Phase Direct Sequencing

\begin{tabular}{|c|c|c|c|}
\hline \multirow{2}{*}{$\begin{array}{l}\text { Coding exon } \\
\text { primer } \operatorname{set}^{*}\end{array}$} & \multirow{2}{*}{$\begin{array}{l}\text { Genomic sequence } \\
\text { amplified }^{\ddagger}\end{array}$} & \multicolumn{2}{|c|}{ Oligonucleotide primers } \\
\hline & & Sense & Antisense \\
\hline $1 \mathrm{~A}$ & $-130-120$ & $5^{\prime}$-gagaccaggagtcagactgt- $3^{\prime}$ & $5^{\prime}$-agacgactgaggatggcaac- $3^{\prime}$ \\
\hline $1 \mathrm{~B}$ & $-130-120$ & $5^{\prime}$-gagaccaggagtcagactgt- $3^{\prime}$ & $5^{\prime}$-ạgacgactgaggatggcaac- $3^{\prime}$ \\
\hline $2-3 A$ & $2911-3309$ & $5^{\prime}$-GCCGCC(GAATTC)tgacaactgccttggtc-3' & $5^{\prime}$-GCCGCC(GAATTC)ctgttctgacaaacctcct-3' \\
\hline $2-3 B$ & $2911-3360$ & $5^{\prime}-c$ ccacccttcctgtggecag-3' & $5^{\prime}$-GCCGCC $\left(\right.$ GAATTC)ctgttctgacaaacctcct- $3^{\prime}$ \\
\hline $4 \mathrm{~A}$ & $3520-3710$ & $5^{\prime}$-GCCGCC(GAATTC)gcctaacetgtgacagtct- $3^{\prime}$ & $5^{\prime}-\overline{\text { GCCGCC }}\left(\right.$ GAATTC)actgggettcccattagct- $3^{\prime}$ \\
\hline 4B & $3520-3770$ & $5^{\prime}-\overline{\text { GCCGCC }}\left(\right.$ GAATTC)gcctaacetgtgacagtct- $3^{\prime}$ & $5^{\prime}$-ạgcgggacgggctttagcta-3' \\
\hline $5-6 A$ & $4012-4298$ & $5^{\prime}$ - $\overline{\text { GCCGCC}}\left(\right.$ GAATTC)gagcacctgattgattgac- $3^{\prime}$ & $5^{\prime}$-GCCGCC(GAATTC)agacctagcatactagg- $3^{\prime}$ \\
\hline $5-6 \mathrm{~B}$ & $3951-4298$ & 5 -gectctgtccccatcatgaa- $3^{\prime}$ & $5^{\prime}$ - $\overline{\text { GCCGCC }}\left(\right.$ GAATTC)agacctagcatactagg- $3^{\prime}$ \\
\hline 7A & $4546-4796$ & $5^{\prime}$-GCCGCC(GAATTC)ggctccaccactgaagtag-3' & $5^{\prime}$-GCCGCC$($ GAATTC)tcaggccccaaagggaaag-3' \\
\hline 7B & $4546-4796$ & $5^{\prime}$-gectccaccactgaagt- $3^{\prime}$ & $5^{\prime}$ - $\overline{\text { GCCGCC }}($ GAATTC)tcaggccccaaagggaaag-3' \\
\hline $8 \mathrm{~A}$ & $4881-5119$ & $5^{\prime}$-GCCGCC(GAATTC)cgagagagaatagaggtga- $3^{\prime}$ & $5^{\prime}$-GCCGCC$(G A A T T C)$ acactaggcaggtcactgtt- $3^{\prime}$ \\
\hline $8 \mathrm{~B}$ & $4881-5119$ & $5^{\prime}$ - $\overline{\text { GCCGCC }}($ GAATTC)cgagagagaatagaggtga-3' & $5^{\prime}$-ạacactaggcagtcactgt- $3^{\prime}$ \\
\hline $9 A$ & $5099-5293$ & $5^{\prime}$ - $\overline{\text { GCCGCC }}\left(\right.$ GAATTC)aacagtgactgcctagtgt- $3^{\prime}$ & $5^{\prime}$-GCCGCC(GAATTC)tgtctttttcettggctgc-3' \\
\hline 9B & $5061-5293$ & $5^{\prime}$-țtgcccagaagatgcaggg- $3^{\prime}$ & $5^{\prime}$-GCCGCC $\left(\right.$ GAATTC)tgtcttttccttggctgc- $3^{\prime}$ \\
\hline $10 \mathrm{~A}$ & $6295-6539$ & 5 '-GCCGCC(GAATTC)aaagacagactcaggcaga & $5^{\prime}$ - $\overline{\text { GCCGCC}}\left(\right.$ GAATTC)taaggcagaaaggagatgc- $3^{\prime}$ \\
\hline $10 \mathrm{~B}$ & $6295-6590$ & $5^{\prime}$-GCCGCC $($ GAATTC)aaagacagactcaggcaga & $5^{\prime}$-ạtcgcttcacacaatcata-3' \\
\hline $11 \mathrm{~A}$ & $7014-7258$ & $5^{\prime}-\overline{\text { GCCGCC}}\left(\right.$ GAATTC)catctcactgccaggtgct- $3^{\prime}$ & $5^{\prime}$-GCCGCC(GAATTC)cggtagcatcccaaggtct-3 \\
\hline $11 \mathrm{~B}$ & $7014-7258$ & $5^{\prime}$-çatctcactgccaggtgc- $3^{\prime}$ & $5^{\prime}$ - $\overline{\text { GCCGCC }}($ GAATTC)cggtagcatcccaaggtct-3 \\
\hline $12 \mathrm{~A}$ & $7333-7554$ & $5^{\prime}$-GCCGCC(GAATTC)cctgatgtcctaggatgtt-3' & $5^{\prime}$-GCCGCC$(G A A T T C)$ gtaagaaatcttccetgcc- $3^{\prime}$ \\
\hline 12B & $7281-7554$ & $5^{\prime}$-agtagatagaggtggtccca-3' & $5^{\prime}$ - $\overline{\text { GCCGCC }}\left(\right.$ GAATTC)gtaagaaatcttccetgcc- $3^{\prime}$ \\
\hline $13 \mathrm{~A}$ & $7641-7848$ & $5^{\prime}$-GCCGCC(GAATTC)cagtgatgtcctcacagtctg- $3^{\prime}$ & $5^{\prime}$ - $\overline{\text { GCCGCC }}\left(\right.$ GAATTC)tacctagaaacetgggatgc- $3^{\prime}$ \\
\hline 13B & $7641-7840$ & $5^{\prime}$ - $\overline{\text { GCCGCC }}\left(\right.$ GAATTC)cagtgatgtcctcacagtctg- $3^{\prime}$ & $5^{\prime}$-çtacctagaaacctgggatg-3' \\
\hline $14-15 A$ & $7830-8061$ & $5^{\prime}$-GCCGCC $\left(\right.$ GAATTC)gcatcccaggtttctaggt- $3^{\prime}$ & $5^{\prime}$-GCCGCC(GAATTC)tctgtgccccacaaacca-3' \\
\hline $14-15 B$ & $7830-8560$ & $5^{\prime}$ - $\overline{\text { GCCGCC }}\left(\right.$ GAATTC)gcatcccaggtttctaggt- $3^{\prime}$ & $5^{\prime}$-ạagggctttgtgtttgttcc- $3^{\prime}$ \\
\hline
\end{tabular}

* A, Primer sets for SSCP analysis; B, primer sets for solid phase direct sequencing, dot indicates biotinylated nucleotide. $\quad{ }^{\ddagger} \mathrm{HMB}$-synthase genomic sequences in lower case letters, EcoRI recognition sites in parentheses, underlined nucleotides represent additional non-HMB-synthase nucleotides to facilitate restriction enzyme cleavage. Genomic sequence position from Yoo et al. (10).

flanking intronic regions were synthesized using biotinylated phosphoramidites in a synthesizer (model 380B; Applied Biosystems, Inc.) (Table I). After amplification of genomic DNA as described above, an aliquot $(40 \mu \mathrm{l})$ of the amplified product was denatured and the biotinylated single strands were isolated by affinity capture using streptavidin-coated magnetic beads (Dynal, Inc., Great Neck, NY) (59), and then the biotinylated single-stranded PCR products were sequenced as described above.

Mutation confirmation in genomic DNA. Nucleotide changes detected by direct sequencing were confirmed in genomic DNA isolated from peripheral blood leukocytes or lymphoid cells $(53,54)$ from the patients and appropriate family members by restriction endonuclease analyses or by dotblot hybridization with allele-specific oligonucleotides (ASOs). Computerassisted analyses revealed that five of the mutations obliterated restriction sites, permitting rapid analysis of the appropriate exons amplified from genomic DNA with the indicated biotinylated primer set as described above (Table I). For restriction analyses, an aliquot $(10 \mu \mathrm{l})$ of each amplification product was digested for $4 \mathrm{~h}$ with the appropriate restriction endonuclease (New England Biolabs Inc., Beverly, MA) and electrophoresed in agarose or polyacrylamide gels as follows: M1I: digested with NlaIII at $37^{\circ} \mathrm{C}$, electrophoresed in $8 \%$ polyacrylamide gels; V93F: BstNI at $65^{\circ} \mathrm{C}, 2 \%$ agarose gels; R201W: MspI at $37^{\circ} \mathrm{C}, 2 \%$ agarose gels; C247F: Fnu4HI at $37^{\circ} \mathrm{C}, 4 \%$ agarose gels; and $\mathrm{W} 283 \mathrm{X}$ : HinfI at $37^{\circ} \mathrm{C}, 12 \%$ polyacrylamide gels. The gels were stained with ethidium bromide $(0.5 \mu \mathrm{g} / \mathrm{ml})$ and then visualized under a long-wave ultraviolet light. The R116W mutation was confirmed by dot-blot hybridization of exon 8 amplified from genomic DNA, with the normal (5'-GTTTTCCCGCCTGGGGG-3') and mutationspecific (5'-GTTTTCCCACCTGGGGG-3') oligonucleotides that were endlabeled with $\left[\gamma-{ }^{32} \mathrm{P}\right] \mathrm{A} \overline{\mathrm{TP}}(60)$ as described previously (61). The over- night hybridization and washes were performed at $56^{\circ} \mathrm{C}$. Membranes were exposed to Kodak XAR-5 film with an intensifying screen for $\sim 6 \mathrm{~h}$.

Prokaryotic expression and characterization of $H M B$-synthase mutations. The normal and mutant HMB-synthase alleles were expressed in Escherichia coli using the pKK233-2 vector (Pharmacia LKB Biotechnology Inc., Piscataway, NJ) as described previously (62). To introduce each of the mutations into the pKK-HMB-synthase (pKK-HMBS) expression construct, the "megaprimer" method for site-directed mutagenesis was used (63). In this mutagenesis strategy, three oligonucleotide primers were used to perform two rounds of PCR. The product of the first amplification, which incorporated the mutation, was used as a megaprimer for the second amplification, which generated a larger product containing the required cDNA sequence and appropriate restriction sites for cassette subcloning. All amplifications were performed for 30 cycles with denaturation at $94^{\circ} \mathrm{C}$ for $1 \mathrm{~min}$, annealing at $60^{\circ} \mathrm{C}$ for 1 min, and extension at $72^{\circ} \mathrm{C}$ for $1 \mathrm{~min}$. For the V93F mutation, sense and antisense primers MP1 (5'-GCGGCGGAATTCCATGGCTGGTAACGGCAATGC-3') and MP2 (5'-GAACAAACAGGTCCACTTC$3^{\prime}$, mutation underlined) were used to generate the 132-bp megaprimer product. The amplification product was gel-purified and used as the sense primer to amplify a 1,132-bp fragment in a reaction with the antisense primer MP3 (5'-GCCGCCGCCAAGCTTCTGTGCCCCACAAACCA-3') and pKK-HMBS DNA as template. The second amplification product was digested with $\mathrm{KpnI}$ and NsiI, and the KpnI/NsiI fragment was ligated as a cassette into the corresponding sites in pKKHMBS, generating the mutant construct pKK-HMBS-V93F. The $\mathrm{R} 116 \mathrm{~W}$ mutation was introduced into the expression construct using sense primer MP1 and antisense primer MP4 (5'-TCCCACTTGCAG- 
ATGGCTC-3') to amplify the 363-bp megaprimer. The gel-purified megaprimer was then used as the sense primer, together with antisense primer MP5 (5'-CCCATCCTTCATAGCTG-3') and pKK-HMBS as template DNA, to amplify an 832-bp product. The 832-bp PCR product was digested with NsiI and KpnI. The Nsil/KpnI fragment was cassetteligated into pKK-HMBS, generating the mutant construct pKK-HMBSR116W. For the R201W mutation, the sense primer MP1 and antisense primer MP6 (5'-CACAAGCATACATGCATTCCTCAGGGTGCAGGATCTGCCCAACCCAGTTGTGCCA-3' containing an Nsil site) were used to amplify a $6 \overline{58}$-bp product which was digested with Kpn1 and NsiI and cassette-ligated into pKK-HMBS, producing pKK-HMBSR201W. For the C247F mutation, sense primer MP7 (5'-GTTCAGTGCCATCATCCTG-3') and antisense primer MP8 (5'-TCAGCGATGAAGCGAAGCAG-3') were used to amplify a 205-bp megaprimer. The purified megaprimer was used as the sense primer to generate a 575-bp PCR product with antisense primer MP4, which was then digested with Nsil and $\mathrm{XbaI}$ and cassette-ligated to corresponding cloning sites of pKK-HMBS, yielding pKK-HMBS-C247F. For the W283X mutation, sense primer MP9 (5'-GGAGGAGTCTGAAGTCTAGACG$\left.3^{\prime}\right)$ and antisense primer MP4 were used to generate a 282-bp megaprimer. The purified megaprimer was used as the antisense primer to produce a PCR product with sense primer MP10 (5'-TGTGGTGGGAACCAGCT-3'). The 697-bp PCR product was digested with Nsil and $\mathrm{XbaI}$ and cassette-ligated into pKK-HMBS, resulting in pKK-HMBSW283X. The entire coding region of each expression construct was sequenced to confirm its authenticity. After transfection of $E$. coli, single colonies were isolated and the inserts were sequenced to confirm the presence of the desired mutation. Transfection, bacterial growth, isopropylthiogalactoside induction, and HMB-synthase assays were performed as described previously (62). For enzyme stability studies, samples from the bacterial lysates, equalized for enzymatic activity, were incubated at $65^{\circ} \mathrm{C}$ for $180 \mathrm{~min}$. Aliquots were removed at timed intervals and placed on ice, and the HMB-synthase activity was determined as described.

In vitro coupled transcription/translation of normal and mutant $c D N A$. The normal housekeeping and erythroid-specific cDNAs encoding HMB-synthase were subcloned into the prokaryotic expression vectors pET5a and pET11a (Novagen, Inc., Madison, WI), which were designated pET-HMBSh and pET-HMBHe, respectively. The V93F, R116W, R201W, C247F, and W283X mutations were introduced into pET-HMBSh by digesting the respective pKK-HMBS expression construct with $\mathrm{KpnI}$ and $\mathrm{XbaI}$ and cassette-ligating the $\mathrm{KpnI} / \mathrm{XbaI}$ fragment into the pET-HMBSh vector. The M1I mutation was introduced into the pET-HMBS vector by the megaprimer site-directed mutagenesis strategy (63). The sense primer MP11 (5'-TTAATACGACTCACTATAGG-3', the 20-nt pET vector T7 promoter) and the antisense primer (5'-TACCAGATATATGTATCTCC-3') were used to generate a 92-bp megaprimer which contained a $\mathrm{Xbal}$ site between the $\mathrm{T} 7$ promoter and the HMB-synthase initiation codon. The megaprimer was purified and used as sense primer, together with antisense primer MP12 (5'-GTCCTTCAAGGAGTAA-3') to amplify a 379-bp product, which was digested with XbaI and $\mathrm{KpnI}$ and cassette-ligated into pET-HMBS generating pET-HMBS-M1I. Each pET expression construct was confirmed by sequencing. The normal and mutant HMB-synthase constructs were transcribed and translated in vitro using the $\mathrm{TNT}^{\mathrm{TM}}$ Coupled Reticulocyte Lysate System according to the manufacturer's instructions (Promega Corp.). Aliquots $(5 \mu \mathrm{l})$ of the translated radiolabeled products were denatured at $100^{\circ} \mathrm{C}$ for $5 \mathrm{~min}$ and then analyzed by gel electrophoresis in an $8 \%$ SDS-PAGE. The gel was fixed with $5 \%$ methanol and $5 \%$ acetic acid for 15 min and incubated in autofluor (National Diagnostics, Inc., Somerville, NJ) for $30 \mathrm{~min}$ to enhance the signal. The gel was dried and exposed to Kodak XAR-5 film for $10 \mathrm{~h}$.

\section{Results}

Identification of HMB-synthase V93F, R116W, R201W, and $C 247 F$ mutations by SSCP. Of the original 10 unrelated AIP heterozygotes screened for 8 known mutations (29-35), 2 had R167Q (proband 1 and 2) and 1 had R167W (proband 3). For identification of the mutations in the remaining 7 unrelated AIP patients, each of the $15 \mathrm{HMB}$-synthase-coding exons was amplified from lymphoblast genomic DNA for SSCP analysis using primers designed to include the intron/exon boundaries (10). The SSCP profiles for proband 4 (V93F), probands 5 and $6(\mathrm{R} 116 \mathrm{~W})$, proband $7(\mathrm{R} 201 \mathrm{~W})$, and proband 8 (C247F) revealed mobility shifts in exons $7,8,10$, and 12 , respectively (Fig. 2; R201W and C247F not shown). When each of these exons was amplified from the respective proband's genomic DNA and sequenced, single point mutations were identified which predicted amino acid substitutions (Fig. 3, B-E). Proband 4 had a $G$ to $T$ transversion of nucleotide 277 in exon 7 which predicted a valine to phenylalanine substitution at residue 93 (designated V93F). Probands 5 and 6 had a $\mathrm{C}$ to $\mathrm{T}$ transition of nucleotide 346 in exon 8 which would cause an arginine to tryptophan substitution in residue $116(\mathrm{R} 116 \mathrm{~W})$. Proband 7 had a $\mathrm{C}$ to $\mathrm{T}$ transition at nucleotide 601 in exon 10 predicting an arginine to tryptophan substitution in residue 201 (R201W). Proband 8 had a G to T transversion of nucleotide 740 in exon 12 which would change a cysteine to phenylalanine in residue 247 (C247F). SSCP analysis of all other exons in the five probands studied did not reveal any mobility shifts resulting from coding region mutations. However, three additional mobility shifts were detected (10) that resulted from intronic polymorphisms in genomic positions 3581A/G (BsmA1), 7064C/A (Hinf1), and 7998G/A (MnlI).

Identification of M1I and W283X by direct solid-phase sequencing. All 15 HMB-synthase exons and flanking regions from probands 9 and 10 were amplified with 12 biotinylated primer sets and were sequenced directly using a solid-phase strategy. In proband 9, a $\mathrm{G}$ to $\mathrm{A}$ transition of nucleotide 3 in exon 1 predicted a methionine to isoleucine substitution (M1I) in the initiation of translation codon (Fig. $3 \mathrm{~A}$ ). In proband 10, a $\mathrm{G}$ to $\mathrm{A}$ transition of nucleotide 848 in exon 14 predicted a tryptophan to stop substitution (W283X) (Fig. $3 F$ ). No other changes were detected in the amplified products from these probands. Initial confirmation of the above mutations was made by demonstrating these lesions in genomic DNA from the respective probands and their available family members by restriction endonuclease digestion or by dot-blot hybridization with ASOs. As shown in Fig. 4, the M1I mutation which obliterated the only NlaIII site in exon 1 was demonstrated in amplified genomic DNA containing exon 1 from proband 9 and several first degree relatives. The proband, her mother, brother, and daughter each had the undigested 250-bp fragment representing the mutant allele, as well as the digested 133- and 117-bp fragments from the normal allele, confirming the inheritance of this allele in these symptomatic individuals. Analogously, the V93F, R201W, C247F, and W283X mutations were each confirmed in the respective exon amplified from genomic DNA, by digestion with a specific restriction enzyme whose cleavage site was obliterated by the mutation. For each mutation, the restriction enzyme and fragment sizes were: V93F, BstN1 (mutant 159-, normal 116- and 43-, and constant 114-bp fragments); R201W, MspI (mutant 162-, normal 84- and 78-, and constant 107-bp fragments); C247F, Fnu4HI (mutant 144, normal 118- and 88-, and constant 101-bp fragments); and W283X, HinfI (mutant 154-, normal 147- and 7-, and constant 99-bp fragments). The R116W mutation was confirmed by amplification of exon 8 
EXON 7

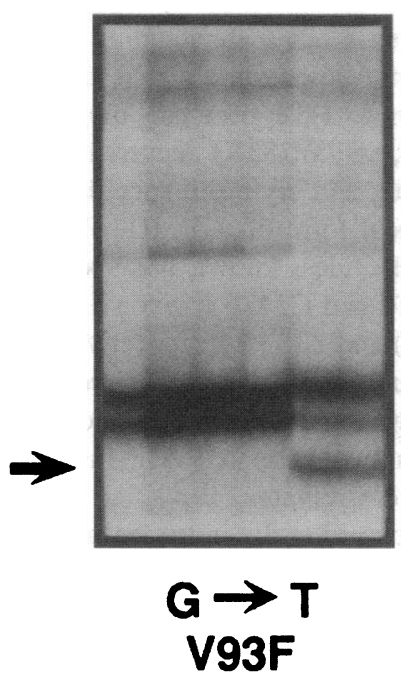

EXON 8

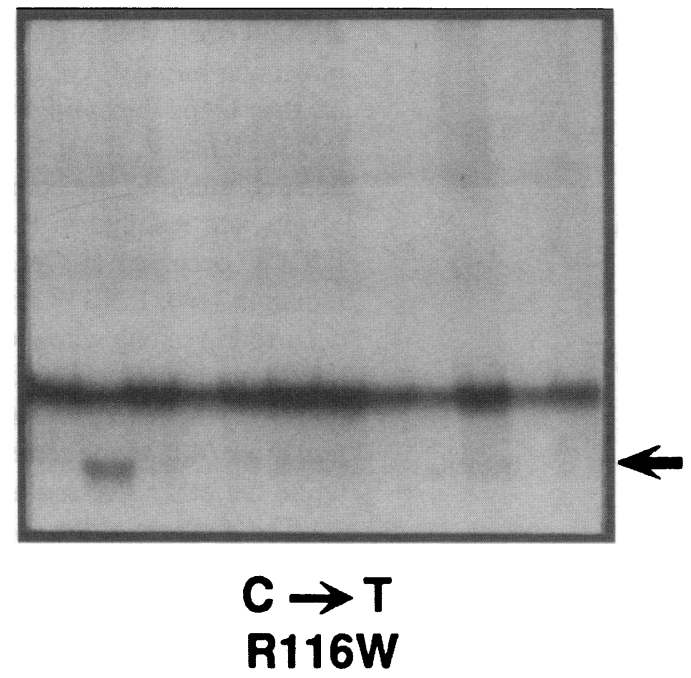

Figure 2. SSCP analysis of HMB-synthase coding exons 7 and 8 from unrelated AIP probands 4 and 5 . Arrows indicate the mobility shifts. See text for details. from genomic DNA of probands 5 and 6 (respective first degree relatives) and dot-blot hybridization using ASOs (data not shown). In each of these families, the respective mutation was identified in genomic DNAs from the proband, from other affected family members, and from previously undiagnosed relatives (in certain families).

Prokaryotic expression of the HMB-synthase mutations. To further characterize the HMB-synthase mutations, pKK-HMBS expression vectors for each of the mutant alleles were constructed, expressed in $E$. coli, and the enzymatic activity and stability of the recombinant proteins were determined. Table II shows the HMB-synthase activities of the expressed normal allele and the V93F, R116W, R201W, C247F, and W283X alleles after transformation and isopropylthiogalactoside induction. Note that the R201W, C247F, and W283X mutations expressed enzymes with significant residual activity (10-42\% of the normal mean), while the activities of the V93F and R116W mutations were $<2 \%$ of the mean level expressed by the normal allele. Fig. 5 compares the relative stabilities of the expressed R201W, C247F, W283X, and normal HMB-synthase proteins when incubated at $65^{\circ} \mathrm{C}, \mathrm{pH} 8.2$. The half-life of the normal enzyme was $\sim 145 \mathrm{~min}$, whereas the half-lives for both the R201W and C247F enzymes were $\sim 25$ and $20 \mathrm{~min}$, respectively, indicating that the mutant proteins had less than onesixth the stability of the normal enzyme under these conditions. The R201W enzyme, which had $>40 \%$ of normal mean activity when expressed in $E$. coli, was rapidly inactivated to levels $<5 \%$ of initial activity at $180 \mathrm{~min}$. The C247F enzyme, which had $\sim 10 \%$ of normal mean activity when expressed in $E$. coli, retained $\sim 10 \%$ of initial activity at $180 \mathrm{~min}$ of heat inactivation. Of interest, the truncated W283X enzyme had a normal thermostability profile.

Characterization of the MII mutation causing variant AIP. Erythrocytes from proband 9 with AIP and her available first degree relatives were assayed for HMB-synthase. Fig. 6 shows the enzymatic activities in unrelated heterozygotes with classical AIP, proband 9 and available family members, and unrelated normal individuals. Notably, the proband and those with the
M1I mutation (her mother, brother, and daughter) had normal erythrocyte HMB-synthase activities.

To characterize the expression of the M1I mutation, particularly to determine its effect on initiation of translation, the M1I mutation was introduced into the pET prokaryotic expression vector by site-directed mutagenesis. For comparison, pET expression constructs containing the normal housekeeping and erythroid-specific cDNAs and each of the other HMB-synthase mutations were made. Each construct was transcribed and translated in vitro and the translated radiolabeled products were assessed by SDS-PAGE. As shown in Fig. 7, the normal housekeeping expression construct, pET-HMBSh, which contains the initiation codons for both the housekeeping and erythroid enzymes encoded two polypeptides of 42 and $40 \mathrm{kD}$, consistent with the translation of both the housekeeping and erythroid-specific enzymes. In contrast, the normal erythroidspecific expression construct, pET-HMBSe, expressed the 40$\mathrm{kD}$ erythroid-specific protein as well as a $33.5-\mathrm{kD}$ polypeptide, whose translation was initiated by the next downstream ATG (at cDNA codon 56) in the pET-HMBSe construct. Notably, the pET-HMBS-M1I construct only expressed the $40-\mathrm{kD}$ polypeptide whose translation was initiated by the downstream erythroid-specific ATG (at codon 18). The pET constructs containing the V93F, R116W, R201W, and C247F mutations expressed both the $42-$ and $40-\mathrm{kD}$ polypeptides, demonstrating the stability and translation of each of the mutant mRNAs. In contrast, the W283X construct encoded 31- and 29-kD polypeptides, consistent with the truncation of 78 amino acids after the abberrant stop triplet at codon 283 .

\section{Discussion}

The identification and characterization of the mutations in the HMB-synthase gene causing AIP have increased our understanding of the molecular basis of variant $\operatorname{AIP}(22,23)$, identified the molecular heterogeneity underlying both the classical and variant forms (29-41), permitted the precise diagnosis of asymptomatic heterozygotes $(22,23,29-41)$, and provided the 


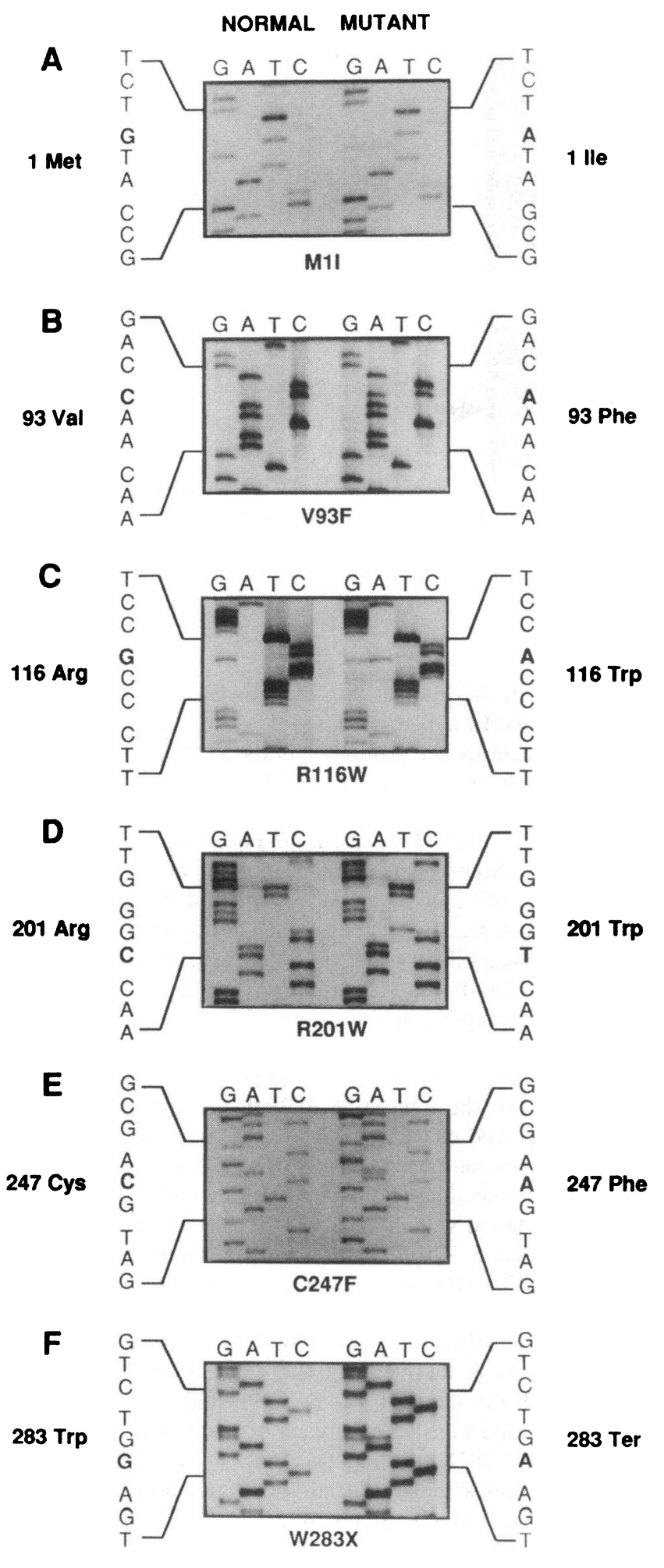

Figure 3. Identification of exonic mutations in the HMB-synthase gene causing AIP. Partial DNA sequences of the PCR-amplified products from genomic DNAs of unrelated AIP patients showing: $(A)$ the $\mathrm{G}$ to A transition of nucleotide 3 predicting a methionine to isoleucine substitution at residue 1 (M1I); (B) a C to A transversion of nucleotide 277 encoding an alanine to phenylalanine replacement at residue 93 (V93F); (C) a $\mathrm{G}$ to $\mathrm{A}$ transition of nucleotide 346 resulting in an arginine to tryptophan change at residue $116(\mathrm{R} 116 \mathrm{~W}) ;(D)$ the $\mathrm{C}$ to $\mathrm{T}$ transition opportunity for structure-function correlations of the human enzyme. Here, six new mutations in the HMB-synthase gene are described which further increase our understanding of the molecular basis of AIP and the synthesis, structure, and function of this heme biosynthetic enzyme. Five of these mutations (V93F, R116W, R201W, C247F, and W283X) occurred in codons common to the housekeeping and erythroid-specific transcripts and resulted in the classical form of AIP. R116W and R201W occurred at CpG dinucleotides, known hot spots for mutation (64). R201W in exon 10 and C247F in exon 12 each occurred in exons where $6(25 \%)$ and $8(33 \%)$, respectively, of the 24 previously known AIP mutations had been located (65). R116W, which was recently found to be a common Dutch AIP mutation (40), was identified in two unrelated AIP families, while the other five mutations were private.

The sixth mutation (M1I) occurred at the initiation methionine of the housekeeping transcript and caused the variant form of AIP. Affected members of this family had normal erythrocytic HMB-synthase activity (Fig. 6) and presumably had halfnormal activity of the housekeeping isozyme which was responsible for the disease manifestations in liver, kidney, brain, and other tissues. Consistent with this concept, the coupled in vitro transcription/translation of the M1I allele resulted in the synthesis of only the $40-\mathrm{kD}$ erythroid-specific enzyme, whereas the normal housekeeping sequence encoded both the $40-\mathrm{kD}$ erythroid-specific and the 42-kD housekeeping isozymes (Fig. 7). These in vitro findings support the prediction that the RNA polymerase fails to recognize the mutated housekeeping translation start codon in vivo. Thus, M1I is the third mutation identified that causes variant AIP, the other two lesions being RNA splicing defects at the exon 1 /intron 1 boundary $(22,23)$.

These six new mutations were identified by two different strategies: (a) SSCP screening of PCR-amplified exonic and flanking intronic sequences followed by solid-phase direct sequencing; and (b) solid-phase direct sequencing of singlestranded PCR products amplified from genomic DNA with biotinylated primers. SSCP analysis revealed mobility shifts in exons $2,7,8,10$, and 12 in amplified genomic DNA from five of the seven unrelated AIP patients studied. The nucleotide changes causing these shifts were identified by solid-phase direct sequencing. In addition to four detected mutations (V93F, R116W, R201W, and C247F), a common new polymorphism (3119 g/t), which caused the mobility shift in exon 2 PCR product, was found in the $5^{\prime}$ region of intron 2 . However, it should be noted that the SSCP technique does not detect all mutations (e.g., reference 66). To detect the remaining two mutations (M1I and W283X), single-stranded solid phase direct sequencing of the amplified products from genomic DNA using biotinylated primers proved successful. Thus, for mutation analysis in the HMB-synthase gene, detection techniques such as SSCP and denaturing gradient gel electrophoresis are useful $(41,66)$; however, it may be more efficient to directly sequence all amplified codons and their intron/exon boundaries. More-

of nucleotide 601 predicting an arginine to tryptophan substitution at residue 201 (R201W); (E) a C to A transversion of nucleotide 740 encoding a cysteine to phenylalanine replacement at residue 247 $(\mathrm{C} 247 \mathrm{~F})$; and $(F)$ a $\mathrm{G}$ to $\mathrm{A}$ transition of nucleotide 849 resulting in a tryptophan to a stop codon at residue 283 (W283X). 

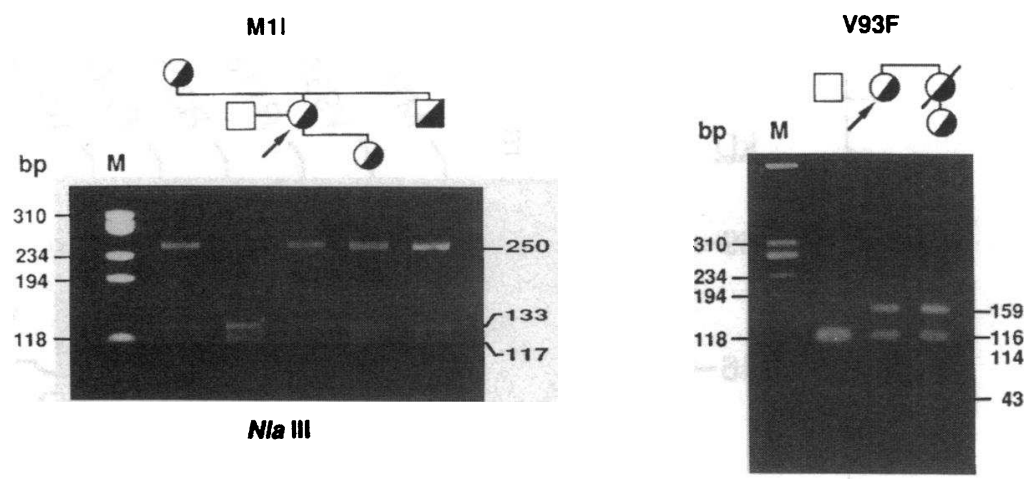

Bst NI

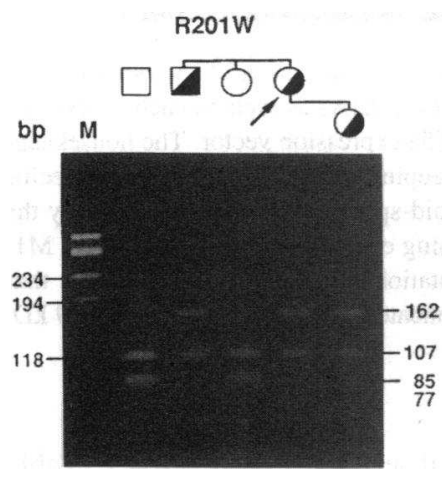

Msp I

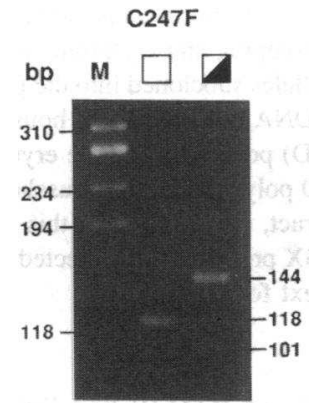

Fnu4 HI

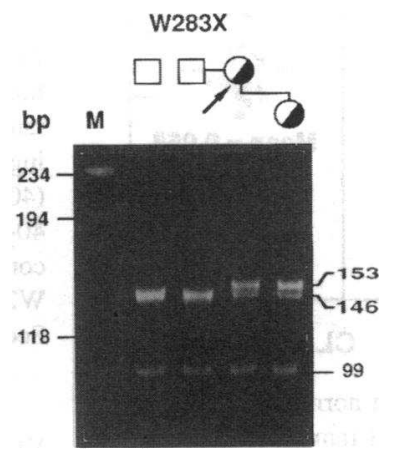

Hinf I
Figure 4. Amplification assays used to confirm the HMB-synthase M1I, V93F, R201W, $\mathrm{C} 247 \mathrm{~F}$, and W283X mutations. For each mutation, the ethidium bromide-stained agarose (V93F, R201W, C247F) or polyacrylamide (M1I, W283X) electrophoretic gel shows digestion with the indicated restriction endonuclease of the respective normal or mutant sequence in amplified genomic DNA of AIP heterozygotes and unaffected family members. Arrows indicate probands; $M$, DNA base pair markers. See text for details. over, even if a mutation is detected by SSCP or denaturing gradient gel electrophoresis, it is necessary to sequence the remainder of the coding region and flanking intronic sequences to eliminate the possibility of a second mutation as well as to exclude the possibility that the detected base substitution is a polymorphism.

Prokaryotic expression of the HMB-synthase mutant alleles revealed that the V93F and R116W mutations produced little, if any, enzymatic activity (Table II). In contrast, the R201W and C247F mutant alleles produced $\sim 40$ and $10 \%$ of the activity expressed by the normal allele, respectively. Heat inactivation studies indicated that both proteins were relatively unstable,

Table II. Expression of HMB-Synthase Mutations in E. coli

\begin{tabular}{lrcc}
\hline & \multicolumn{2}{c}{ HMB-Synthase activity } & \\
\cline { 2 - 3 } \multicolumn{1}{c}{ Construct } & Mean & Range* & $\begin{array}{c}\text { Percentage of mean } \\
\text { normal activity }\end{array}$ \\
\hline & U/mg & $\%$ & \\
pKK233-2 & 1.5 & $1.20-1.90$ & 0 \\
pKK-HMBS & 194.0 & $186.00-205.00$ & 100 \\
pKK-HMBS-V93F & 2.3 & $1.98-2.58$ & 1.1 \\
pKK-HMBS-R116W & 2.8 & $2.40-3.32$ & 1.4 \\
pKK-HMBS-R201W & 80.7 & $67.00-88.70$ & 41.6 \\
pKK-HMBS-C247F & 21.3 & $10.80-29.20$ & 11.0 \\
pKK-HMBS-W283X & 20.0 & $18.80-22.20$ & 10.3 \\
\hline
\end{tabular}

*Range represents results of three independent experiments. losing over $90 \%$ of control activity after heating at $65^{\circ} \mathrm{C}$. Presumably, their half-life in heme-producing erythroid cells and in hepatocytes also would be significantly reduced (Fig. 5). Interestingly, W283X produced a mutant protein in which the carboxy-terminal 78 residues were deleted, but retained $\sim 10 \%$

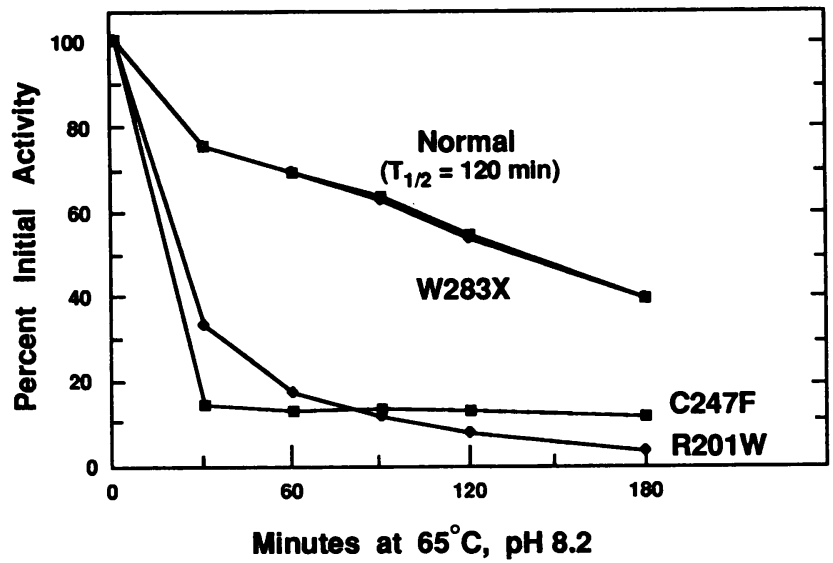

Figure 5. Thermostability of the enzymes expressed in $E$. coli by pKKHMBS (normal allele) and pKK-HMBS-R201W, pKK-HMBS-C247F, and pKK-HMBS-W283X. Cell extracts were incubated at $65^{\circ} \mathrm{C}$ and $\mathrm{pH}$ 8.2 for the indicated times, and the HMB-synthase enzyme activities were determined. The results are expressed as the percentage of initial activity based on the mean of three independent assays for each mutation. 


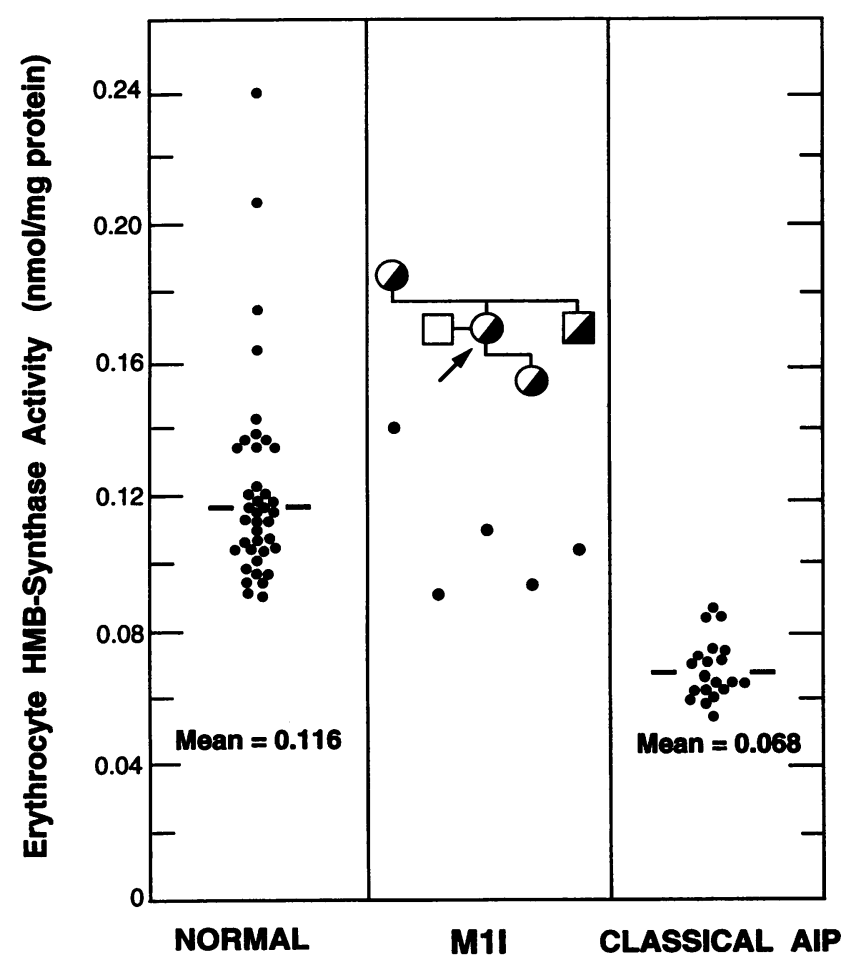

Figure 6. Erythrocyte HMB-synthase activity in normal individuals ( $\boldsymbol{n}$ $=35$ ), classical AIP patients $(n=25)$, and M1I family members as indicated in the pedigree. Note that the HMB-synthase activities of affected M1I family members are within the normal range, consistent with the M1I mutation causing variant AIP.

of the expressed normal activity and was as stable as the normal enzyme in vitro (Fig. 5).

Recently, HMB-synthase purified from $E$. coli was crystallized to a $1.9 \AA$ resolution (67). The crystal structure revealed three domains, domains 1 and 2 were structurally identical to the group II periplasmic binding proteins and the duplicated lobe of the bilobal transferrins. The dipyrromethane cofactor was bound to the sulfur atom of cystine 242 in domain 3 . The cofactor's acetate and proprionate side chains were in a deep cleft between domains 1 and 2 and formed salt-bridge and hydrogen bond interactions with invariant arginine residues (R11, $\mathrm{R} 132$, and R155) and adjacent amino acids in domains 1 and 2 (e.g., F62, D84, S129, T127). Since the $E$. coli and human HMB-synthase amino acid sequences have $45 \%$ homology, it is possible to infer the location and structure/function relationship of certain human HMB-synthase mutations $(35,37)$. For example, Llewellyn et al. (37) described a cross-reacting immunologic material-positive AIP patient with a missense mutation of arginine codon $26(\mathrm{R} 26 \mathrm{H})$, which corresponds to $E$. coli $\mathrm{R} 11$, an invariant arginine which forms a salt bridge with the acidic side chain of the second pyrrole ring of the dipyrrolic cofactor (67). Notably, site-specific mutagenesis of the homologous $E$. coli arginine (R11 to H11) resulted in a enzyme protein with $<1 \%$ of normal activity that could not bind substrate or catalyze chain elongation (68). Presumably, the R26H mutation similarly altered the human enzyme's structure and function.

Additional structure/function correlations can be inferred from the mutations described here (Fig. 8). Human mutations

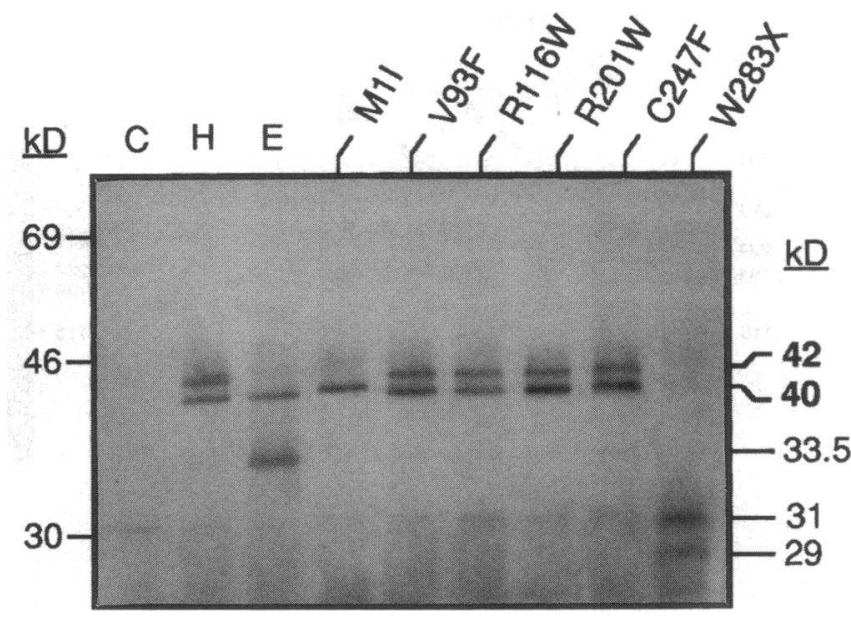

Figure 7. In vitro coupled transcription/translation of the normal housekeeping and erythroid-specific cDNAs as well as each of the mutant alleles subcloned into the pET5a expression vector. The housekeeping cDNA produced both housekeeping ( $42 \mathrm{kD}$ ) and erythroid-specific $(40 \mathrm{kD})$ polypeptides. The erythroid-specific cDNA expressed only the 40-kD polypeptide. No housekeeping enzyme was produced by the M1I construct, consistent with this mutation causing variant AIP. Note that W283X produced the expected truncated polypeptides of 31 and $29 \mathrm{kD}$. See text for details.

V93F and R116W had little, if any, expressed activity (Table II). The human V93F mutation occurred at the corresponding $E$. coli variant residue A78 in domain 2 located in a $\beta$-sheet near a surface loop. Presumably, the replacement of this small, hydrophobic residue with a bulky, aromatic amino acid rendered the enzyme inactive and/or unstable due to alteration of the active site conformation and/or the interface with the adjacent $\alpha$-helix (Fig. 8). Human mutation R116W occurred at a position corresponding to an invariant arginine in $E$. coli (R101) that forms a salt bridge with Glu 231 in domain 3, one of a series of polar interactions positioning domain 3 alongside domain 1 (67). Site-specific mutagenesis of $E$. coli R101 inhibited enzymatic activity (68), consistent with the finding that the homologous human R116W mutation had essentially no expressed activity.

Human mutations R201W and C247F both had residual enzymatic activity, but were unstable. The arginine of human mutation $\mathrm{R} 201 \mathrm{~W}$ corresponds to $E$. coli $\mathrm{R} 182$, a residue that occurs at a surface loop joining an $\alpha$-helix and $\beta$-sheet in domain 1. Expression of the human R201W mutant enzyme in $E$. coli resulted in $\sim 40 \%$ of the activity produced by the normal allele, consistent with the fact that the mutant residue was in a surface loop. However, the mutant enzyme was particularly unstable (Fig. 5) due to the replacement of the polar arginine with the bulkier and more hydrophobic tryptophan which presumably altered the loop's turn configuration and the enzyme's stability. Human residue C247 corresponds to $E$. coli V228, a variant residue in domain 3 involved in a hydrophobic interface with domain 1. The human C247F mutant enzyme had $~ 10 \%$ of normal expressed activity, but was markedly unstable, presumably due to the substitution of the bulky, aromatic residue which interfered with the hydrophobic interactions between domains 1 and 3. Similarly, C247R, another mutation in this codon identified in a classical AIP patient, introduced a large, polar 
Domain 1

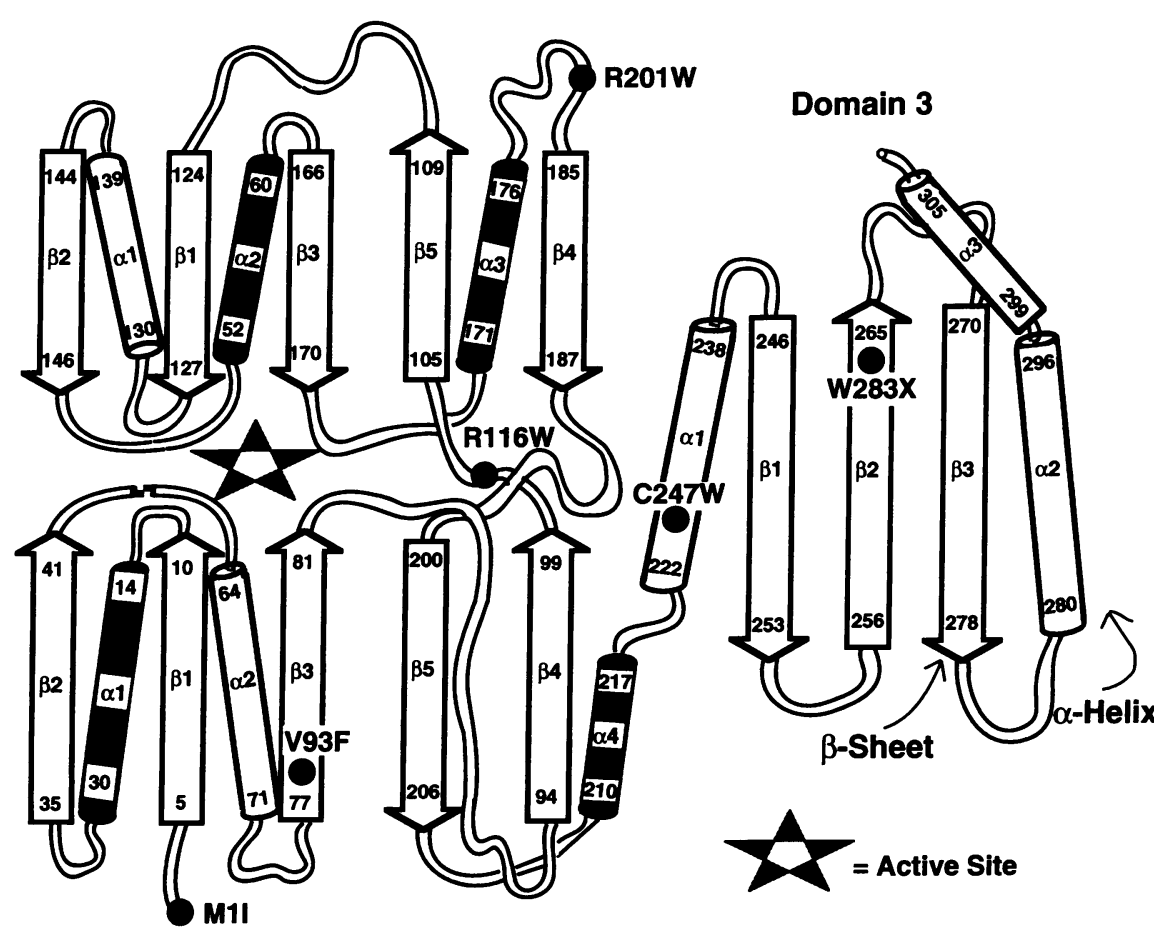

Domain 2
Figure 8. Schematic representation of the secondary structural elements based on the crystal structure of $E$. coli HMB-synthase. Helices are shown as cylinders and are shaded if behind the plane of the $\beta$-sheet (after Louie et al., reference 67). The positions of the M1I, V63F, R116W, R201W, $\mathrm{C} 247 \mathrm{~F}$, and $\mathrm{W} 283 \mathrm{X}$ mutations, as determined by homology comparisons, are indicated. Note that V93F and R116W, which expressed $<2 \%$ of normal activity, occurred near the active site, while the R201W and $\mathrm{C} 247 \mathrm{~F}$ mutations that encode unstable proteins with residual activity occurred in a surface loop (R201W) and in an hydrophobic interface between domains 2 and 3 (C247F). The W283X mutation, which expressed a stable enzyme with $\sim 10 \%$ residual activity, was located in domain 3. arginine, which also interrupted the hydrophobic interactions between domains 1 and 3 (35).

Human mutation W283X, corresponding to E. coli G264, deleted 78 residues from domain 3 , yet retained normal stability and $\sim 10 \%$ of normal expressed activity. Domain 3 of the human HMB-synthase polypeptide has 29 more amino acids than the corresponding $E$. coli domain. Extra residues were inserted into the human sequence between corresponding $E$. coli codons G274 and A279 which occur in the loop following the $\beta$-sheet $\beta 3_{3}$ in domain 3 . Since these 29 residues are highly conserved in humans, mice, and rats, they may be important in positioning the terminal invariant residues and their flanking sequences for extension of the growing pyrrole and/or release of the linear hydroxymethylbilane product (68).

In summary, six new mutations have been identified in the HMB-synthase gene which cause AIP. Not only did these lesions permit precise carrier detection in their respective AIP families, but they revealed a new molecular mechanism for variant AIP and provided further delineation of the genetic heterogeneity underlying classical and variant AIP. Moreover, comparison of the mutated residues with the position of their corresponding residues in the $E$. coli crystal structure provided insight into the structure/function relationships of human HMBsynthase.

\section{Acknowledgments}

The authors thank Lisa Bland and Annie Hernandez for preparation of the manuscript and the following physicians for referral of patients and/ or diagnostic specimens: Dr. Russell Graham (Altamonte Springs, FL), Dr. Thomas W. Sparks (Baton Rouge, LA), Dr. Joseph Hirsch (Louis- ville, KY), Dr. Mary J. Hodak (York, PA), and Dr. Sylvia Bottomley (Oklahoma City, OK).

This research was supported in part by a grant (5 RO1 DK26824) from the National Institutes of Health, a grant (1-0853) from the March of Dimes Birth Defects Foundation, grants (5 MO1 RR00071 and 2 MO1 RR0073) from the National Center for Research Resources, National Institutes of Health for the General Clinical Research Centers at the Mount Sinai School of Medicine and the University of Texas Medical Branch, respectively, a grant (5 P30 HD28822) from the National Institutes of Health to the Mount Sinai Child Health Research Center, and a grant (FD-R-00710) from the Food and Drug Administration Office of Orphan Product Development.

\section{References}

1. Strand, L. J., B. F. Felsher, A. G. Redeker, and H. S. Marver. 1970 Enzymatic abnormality in heme biosynthesis in intermittent acute porphyria. Decreased hepatic conversion of porphobilinogen to porphyrins and increased delta aminolevulinic acid synthetase activity. Proc. Natl. Acad. Sci. USA. 67:13151320.

2. Miyagi, K., R. Cardinal, I. Bossenmaier, and C. J. Watson. 1971. The serum porphobilinogen and hepatic porphobilinogen deaminase in normal and porphyric individuals. J. Lab. Clin. Med. 78:683-695.

3. Strand, L. J., U. A. Meyer, B. F. Felsher, A. G. Redeker, and H. S. Marver. 1972. Decreased red cell uroporphyrinogen I synthetase activity in intermittent acute porphyria. J. Clin. Invest. 51:2430-2536.

4. Meyer, U. A., L. J. Strand, M. Doss, A. C. Rees, and H. S. Marver. 1972. Intermittent acute porphyria: demonstration of a genetic defect in porphobilinogen metabolism. N. Engl. J. Med. 286:1277-1282.

5. Meyer, Y., and R. Schmid. 1978. The porphyrias. In The Metabolic Basis of Inherited Disease. 4th ed. J. B. Stanbury, J. B. Wyngaarden, and D. S. Fredrickson, editors. McGraw-Hill Inc., New York. 1166-1220.

6. Tschudy, D. P., and J. M. Lamon. 1980. Porphyrin metabolism and the porphyrias. In Metabolic Control and Disease. 8th ed. P. K. Bondy and L. Rosenberg, editors. W. B. Saunders Co., Philadelphia. 939-1007.

7. Kappas, A., S. Sassa, R. A. Galbraith, and Y. Nordmann. 1989. The porphyr- 
ias. In The Metabolic Basis of Inherited Disease. 6th ed. C. R. Scriver, A. L. Beaudet, W. S. Sly, and D. Valle, editors. McGraw-Hill Inc., New York. 13051365 .

8. Wang, A. L., F. X. Arrendondo-Vega, P. F. Giampietro, M. Smith, W. F. Anderson, and R. J. Desnick. 1981. Regional gene assignment of human porphobilinogen deaminase and esterase A4 to chromosome 11q23-11qter. Proc. Natl. Acad. Sci. USA. 78:5734-5738.

9. Namba, H., K. Narahara, K. Tsuji, Y. Yokoyama, and Y. Seino. 1991. Assignment of human porphobilinogen deaminase to $11 \mathrm{q} 24.1 \rightarrow \mathrm{q} 24.2$ by in situ hybridization and gene dosage studies. Cytogenet. Cell Genet. 57:105-108.

10. Yoo, H.-W., C. A. Warner, C.-H. Chen, and R. J. Desnick. 1993. Hydroxymethylbilane synthase: complete genomic sequence and amplifiable polymorphisms in the human gene. Genomics. 15:21-29.

11. Chretien, S., A. Dubart, D. Beaupain, N. Raich, B. Grandchamp, J. Rosa, M. Goossens, and P. H. Romeo. 1988. Alternative transcription and splicing of the human porphobilinogen deaminase gene result either in tissue-specific or in housekeeping expression. Proc. Natl. Acad. Sci. USA. 85:6-10.

12. Grandchamp, B., H. de Verneuil, C. Beaumont, S. Chretien, O. Walter, and Y. Nordmann. 1987. Tissue-specific expression of porphobilinogen deaminase. Two isozymes from a single gene. Eur. J. Biochem. 162:105-110.

13. Raich, N., V. Mignotte, A. Dubart, D. Beaupain, P. H. Leboulch, M. Romana, C. Chabret, P. Charnay, T. Papayannopoulou, M. Goossens, and P. H. Romeo. 1989. Regulated expression of the overlapping ubiquitous and erythroid transcription units of the human porphobilinogen deaminase (PBG-D) gene introduced into non-erythroid cells and erythroid cells. J. Biol. Chem. 264:1018610192.

14. Mignotte, V., J. F. Eleouet, N. Raich, and P. H. Romeo. 1989. Cis- and trans-acting elements involved in the regulation of the erythroid promoter of the human porphobilinogen deaminase gene. Proc. Natl. Acad. Sci. USA. 86:65486552 .

15. Raich, N., P. H. Romeo, A. Dubart, D. Beaupain, M. Cohen-Solal, and M. Goossens. 1986. Molecular cloning and complete primary sequence of human erythrocyte porphobilinogen deaminase. Nucleic Acids Res. 14:5955-5968.

16. Anderson, P. M., and R. J. Desnick. 1980. Purification and properties of uroporphyrinogen I synthase from human erythrocytes. Identification of stable enzyme-substrate intermediates. J. Biol. Chem. 255:1993-1999.

17. Anderson, P. M., R. M. Reddy, K. E. Anderson, and R. J. Desnick. 1981. Characterization of the porphobilinogen deaminase deficiency in acute intermittent porphyria. Immunologic evidence for heterogeneity of the genetic defect. J. Clin. Invest. 68:1-12.

18. Desnick, R. J., L. T. Ostasiewicz, P. A. Tishler, and P. Mustajoki. 1985. Acute intermittent porphyria: characterization of a novel mutation in the structural gene for porphobilinogen deaminase. Demonstration of noncatalytic enzyme intermediates stabilized by bound substrate. J. Clin. Invest. 76:865-874.

19. Mustajoki, P., and R. J. Desnick. 1985. Genetic heterogeneity of acute intermittent porphyria: characterization and frequency of porphobilinogen deaminase mutations in Finland. Br. Med. J. 291:505-509.

20. Desnick, R. J., and K. E. Anderson. 1991. Heme biosynthesis and its disorders: the porphyrias and sideroblastic anemias. In Hematology Basic Principles and Practice. R. Hoffman, E. J. Benz, S. J. Shattil, B. Furie, and H. J. Cohen, editors. Churchill-Livingstone, Inc., New York. 350-367.

21. Mustajoki, P. 1981. Normal erythrocyte uroporphyrinogen I synthase in a kindred with acute intermittent porphyria. Ann. Intern. Med. 95:162-166.

22. Grandchamp, B., C. Picat, R. Kauppinen, V. Mignotte, L. Peltonen, P. Mustajoki, P. H. Romeo, M. Goossens, and Y. Nordmann. 1989. Molecular analysis of acute intermittent porphyria in a Finnish family with normal erythrocyte porphobilinogen deaminase. Eur. J. Clin. Invest. 19:415-418.

23. Grandchamp, B., C. Picat, V. Mignotte, J. H. P. Wilson, K. Te Velde, L. Sandkuyl, P. H. Romeo, M. Goossens, and Y. Nordmann. 1989. Tissue-specific splicing mutation in acute intermittent porphyria. Proc. Natl. Acad. Sci. USA. 86:661-664.

24. Lamon, J. M., B. C. Frykholm, and D. P. Tschudy. 1979. Family evaluations in acute intermittent porphyria using red blood cell uroporphyrinogen-1synthase. J. Med. Genet. 16:134-139.

25. McColl, K. E. L., M. R. Moore, G. G. Thompson, and A. Goldberg. 1982. Screening for latent acute intermittent porphyria: the value of measuring both leukocyte $\delta$-aminolevulinate acid synthase and erythrocyte uroporphyrinogen-Isynthase activities. J. Med. Genet. 19:271-276.

26. Bonnati-Pellie, S., L. Phung, and Y. Nordmann. 1984. Recurrence risk estimation of acute intermittent porphyria based on analysis of porphobilinogen deaminase activity: a Bayesian approach. Am. J. Med. Genet. 19:755-762.

27. Pierach, C. A., M. K. Weimer, R. A. Cardinal, C. Bossenmaier, and R. Bloomer. 1987. Red blood cell porphobilinogen deaminase in the evaluation of acute intermittent porphyria. JAMA (J. Am. Med. Assoc.). 257:60-61.

28. Mustajoki, P., and T. Tenhunen. 1985. Variant of acute intermittent porphyria with normal erythrocyte uroporphyrinogen-I-synthase activity. Eur. J. Clin. Invest. 15:281-284.

29. Grandchamp, B., C. Picat, F. de Rooij, C. Beaumont, P. Wilson, J. C.
Deybach, and Y. Nordmann. 1989. A point mutation $G \rightarrow A$ in exon 12 of the porphobilinogen deaminase gene results in exon skipping and is responsible for acute intermittent porphyria. Nucleic Acids Res. 17:6637-6649.

30. Delfau, M. H., C. Picat, F. W. M. de Rooij, K. Hamer, M. Bogard, H. P. Wilson, J. C. Deybach, Y. Nordmann, and B. Grandchamp. 1990. Two different point $\mathbf{G}$ to $A$ mutations in exon 10 of the porphobilinogen deaminase gene are responsible for acute intermittent porphyria. J. Clin. Invest. 86:15111516.

31. Scobie, G. A., D. H. Llewellyn, A. J. Urquhart, S. J. Smyth, N. A Kalsheker, P. R. Harrison, and G. H. Elder. 1990. Acute intermittent porphyria caused by a $\mathrm{C} \rightarrow \mathrm{T}$ mutation that produces a stop codon in the porphobilinogen deaminase gene. Hum. Genet. 85:631-634.

32. Delfau, M. H., C. Picat, F. de Rooij, G. Voortman, J. C. Deybach, Y. Nordmann, and B. Grandchamp. 1991. Molecular heterogeneity of acute intermittent porphyria: identification of four additional mutations resulting in the CRIMnegative subtype of the disease. Am. J. Hum. Genet. 49:421-428.

33. Lee, J.-S., and M. Anvret. 1991. Identification of the most common mutation within the porphobilinogen deaminase gene in Swedish patients with acute intermittent porphyria. Proc. Natl. Acad. Sci. USA. 88:10912-10915.

34. Gu, X.-F., F. de Rooij, G. Voortman, K. Te Velde, Y. Nordmann, and B. Grandchamp. 1992. High frequency of mutations in exon 10 of the porphobilinogen deaminase gene in patients with a CRIM-positive subtype of acute intermittent porphyria. Am. J. Hum. Genet. 51:660-665.

35. Mgone, C. S., W. G. Lanyon, M. R. Moore, and J. M. Connor. 1992. Detection of seven point mutations in the porphobilinogen deaminase gene in patients with acute intermittent porphyria, by direct sequencing of in vitro amplified cDNA. Hum. Genet. 90:12-16.

36. Daimon, M., K. Yamatani, M. Igarashi, N. Fukase, A. Ogawa, M. Tominaga, and H. Sasaki. 1993. Acute intermittent porphyria caused by a $G$ to $C$ mutation in exon 12 of the porphobilinogen deaminase gene that results in exon skipping. Hum. Genet. 92:549-553.

37. Llewellyn, D. H., S. Whatley, and G. H. Elder. 1993. Acute intermittent porphyria caused by an arginine to histidine substitution (R26H) in the cofactorbinding cleft of porphobilinogen deaminase. Hum. Mol. Genet. 2:1315-1316.

38. Mgone, C. S., W. G. Lanyon, M. R. Moore, G. V. Louie, and J. M. Conner. 1993. Detection of a high mutation frequency in exon 12 of the porphobilinogen deaminase gene in patients with acute intermittent porphyria. Hum. Genet. 92:619-622.

39. Gu, X.-F., F. de Rooij, E. de Baar, M. Bruyland, W. Lissens, Y. Nordman, and B. Grandchamp. 1993. Two novel mutations of the porphobilinogen deaminase gene in acute intermittent porphyria. Hum. Mol. Genet. 2:1735-1736.

40. Gu, X.-F., F. de Rooij, J.-S. Lee, K. Te Velde, J. C. Deybach, Y. Nordman, and B. Grandchamp. 1993. High prevalence of a point mutation in the porphobilinogen deaminase gene in Dutch patients with acute intermittent porphyria. Hum. Genet. 91:128-130.

41. Gu, X.-F., F. de Rooij, G. Voortman, K. Te Velde, J.-C. Deybach, Y. Nordmann, and B. Grandchamp. 1994. Detection of eleven mutations causing acute intermittent porphyria using denaturing gradient gel electrophoresis. Hum. Genet. 93:47-52.

42. Llewellyn, D. H., N. A. Kalsheker, G. H. Elder, P. R. Harrison, S. Chretien, and M. Goossens. 1987. A MspI polymorphism for the human porphobilinogen deaminase gene. Nucleic Acids Res. 15:1349.

43. Lee, J.-S., and M. Anvret. 1987. A PstI polymorphism for the human porphobilinogen deaminase gene (PBG). Nucleic Acids Res. 15:6307.

44. Picat, C., F. Bourgeois, and B. Grandchamp. 1988. PCR detection of a C/ $\mathrm{T}$ polymorphism in exon 1 of the porphobilinogen deaminase gene (PBGD). Nucleic Acids Res. 19:5099.

45. Gu, X. F., J.-S. Lee, M. H. Delfau, and B. Grandchamp. 1989. PCR detection of a $\mathrm{G} / \mathrm{T}$ polymorphism at exon 10 of the porphobilinogen deaminase gene. Nucleic Acids Res. 19:1966.

46. Lee, J.-S., M. Anvret, J. Lindsten, L. Lannfelt, P. Gellerfors, L. Wetterberg, Y. Floderus, and S. Thunell. 1988. DNA polymorphisms within the human porphobilinogen deaminase gene in two Swedish families with acute intermittent porphyria. Hum. Genet. 79:379-381.

47. Daimon, M., Y. Morita, K. Yamatani, M. Igarashi, N. Fukase, H. Ohnuma, K. Sugiyama, A. Ogawa, H. Manaka, M. Tominaga, and H. Sasaki. 1993. Two new polymorphisms in introns 2 and 3 of the human porphobilinogen deaminase gene. Hum. Genet. 92:115-116.

48. Schreiber, W. E., A. Jamani, and B. Ritchie. 1992. Detection of a T/C polymorphism in the porphobilinogen gene by polymerase chain reaction amplification of specific alleles. Clin. Chem. 38:2153-2155.

49. Scobie, G. A., A. J. Urquhart, G. H. Elder, N. A. Kalsheker, D. H Llewellyn, J. Smyth, and P. R. Harrison. 1990. Linkage disequilibrium between DNA polymorphisms within the porphobilinogen deaminase gene. Hum. Genet. 85:157-159.

50. Kauppinen, R., L. Peltonen, H. Palotie, and P. Mustajoki. 1992. RFLP analysis of three different types of acute intermittent porphyria. Hum. Genet. 85:160-164. 
51. Lee, J.-S., J. Lindsten, and M. Anvret. 1990. Haplotyping of the human porphobilinogen deaminase gene in acute intemittent porphyria by polymerase chain reaction. Hum. Genet. 84:241-243.

52. Anderson, M. A., and J. F. Gusella. 1984. Use of cyclosporin A in establishing Epstein-Barr virus-transformed human lymphoblastoid cell lines. In Vitro (Rockville). 20:856-858.

53. Levran, O., R. J. Desnick, and E. H. Schuchman. 1991. Niemann-Pick disease: a frequent missense mutation in the acid sphingomyelinase gene in patients of Ashkenazi Jewish ancestry with Types A and B Niemann-Pick disease. Proc. Natl. Acad. Sci. USA. 88:3748-3752.

54. Chirgwin, J. M., A. E. Pryzybyla, R. J. MacDonald, and W. J. Rutter. 1979. Isolation of biologically active ribonucleic acid from sources enriched in ribonuclease. Biochemistry. 18:5294-5299.

55. Orita, M., Y. Suzuki, T. Sekiya, and K. Hayashi. 1989. Rapid and sensitive detection of point mutations and DNA polymorphisms using the polymerase chain reaction. Genomics. 5:874-879.

56. Michaud, J., L. C. Brody, G. Steel, G. Fontaine, L. S. Martin, D. Valle, and G. Mitchell. 1992. Strand-separating conformational polymorphism analysis: efficacy of detection of point mutations in the human ornithine $\delta$-aminotransferase gene. Genomics. 13:389-394.

57. Saiki, R. K., D. H. Gelgard, S. J. J. Stoffer, R. Higuchi, G. T. Horn, K. B. Mullis, and A. Erlich. 1988. Primer-directed enzymatic amplification of DNA with a thermostable DNA polymerase. Science (Wash. DC). 239:487-491.

58. Sanger, F., S. Nicklen, and A. R. Coulson. 1977. DNA sequencing with chain-terminating inhibitors. Proc. Natl. Acad. Sci. USA. 74:5463-5467.

59. Hultman, T., S. Stahl, E. Hornes, and M. Uhlen. 1989. Direct solid phase sequencing of genomic and plasmid DNA using magnetic beads as solid support. Nucleic Acid Res. 17:4937-4946.
60. Sambrook, J., E. F. Fritsch, and T. Maniatis. 1989. Molecular Cloning: A Laboratory Manual. Cold Spring Harbor Laboratory, Cold Spring Harbor, NY. 11.66-11.67.

61. Warner, C. A., H.-W. Yoo, A. G. Roberts, and R. J. Desnick. 1992 Congenital erythropoietic porphyria: identification and expression of exonic mutations in the uroporphyrinogen III synthase gene. J. Clin. Invest. 89:693-700.

62. Tsai, S. F., D. F. Bishop, and R. J. Desnick. 1988. Human uroporphyrinogen III synthase: molecular cloning, nucleotide sequence, and expression of a full length cDNA. Proc. Natl. Acad. Sci. USA. 85:7049-7053.

63. Gobinda, S., and S. Sommer. 1990. The "megaprimer" method of sitedirected mutagenesis. Biotechniques. 8:404-407.

64. Barker, D. F., M. Schafer, and R. White. 1984. Restriction sites containing CpG show a higher frequency of polymorphism in human DNA. Cell. 36:131138.

65. Astrin, K. H., and R. J. Desnick. 1994. Mutation update: molecular basis of acute intermittent porphyria: mutations and polymorphisms in the human hyroxyethylbilane synthase gene. Hum. Mutation. In press.

66. Sheffield, V. C., J. S. Beck, A. E. Kwitek, D. W. Sandstrom, and E. M Stone. 1993. The sensitivity of single strand conformation polymorphism analysis for the detection of single base substitutions. Genomics. 16:325-332.

67. Louie, G. V., P. D. Brownlie, R. Lambert, J. B. Cooper, T. L. Blundell, S. P. Wood, M. J. Warren, S. C. Woodcock, and P. M. Jordan. 1992. Structure of porphobilinogen deaminase reveals a flexible multidomain polymerase with a single catalytic site. Nature (Lond.). 359:33-39.

68. Jordan, P. M., and S. C. Woodcock. 1991. Mutagenesis of arginine residues in the catalytic cleft of Escherichia coli porphobilinogen deaminase that affects dipyrrolmethane cofactor assembly and tetrapyrrole chain initiation and elongation. Biochem. J. 280:445-449. 